\title{
Updates on the Systemic Treatment of Advanced Non-melanoma Skin Cancer
}

\author{
Keiji Tanese*, Yoshio Nakamura, Ikuko Hirai and Takeru Funakoshi \\ Department of Dermatology, Keio University School of Medicine, Tokyo, Japan
}

Non-melanoma skin cancers (NMSCs), which represent a diverse group of cutaneous malignancies, are the most common forms of human neoplasia. The incidence of these diseases is increasing due to a number of factors, including that of increasing human lifespans. The majority of NMSCs are basal cell carcinomas (BCC) and cutaneous squamous cell carcinomas (CSCC), with the remainder being various rare skin cancers, including extramammary Paget's disease (EMPD), Merkel cell carcinoma (MCC), and several skin adnexal carcinomas. Of these, MCC usually shows aggressive behavior with a high mortality rate. On the other hand, BCC, CSCC, EMPD, and skin adnexal tumors usually show an indolent clinical course and metastasize only rarely. Nevertheless, the metastatic forms of these tumors commonly lead to poor patient outcome. A definitive management strategy for the treatment of advanced NMSC has not been established, mainly due to their rarity and lack of reliable information based on well-

OPEN ACCESS

Edited by:

Taku Fujimura

Tohoku University, Japan

Reviewed by:

Takashi Inozume,

University of Yamanashi, Japan

Takeo Maekawa,

Jichi Medical University, Japan

*Correspondence:

Keiji Tanese

tanese@2001.jukuin.keio.ac.jp

Specialty section:

This article was submitted to Dermatology,

a section of the journal

Frontiers in Medicine

Received: 10 June 2019 Accepted: 28 June 2019 Published: 10 July 2019

Citation:

Tanese K, Nakamura Y, Hirai I and Funakoshi T (2019) Updates on the Systemic Treatment of Advanced Non-melanoma Skin Cancer. Front. Med. 6:160

doi: 10.3389/fmed.2019.00160 controlled randomized trials. Chemotherapeutic regimens for treatment of these diseases have been mainly based on the observations of isolated, small case series or clinical trials with a limited numbers of patients. However, accumulating evidence regarding their pathobiological backgrounds as well as recent advances in molecular biotechnology have facilitated the development of novel drugs for treatment of these diseases. Over the past decade, the U.S. Food and Drug Administration has approved several molecular targeting therapies, including Hedgehog inhibitors for BCC, monoclonal antibodies targeting anti-programmed death ligand-1 and anti- programmed cell death 1 (PD-1) for MCC, and anti-PD-1 for cSCC. Here, we review their clinical utility and discuss updated systemic treatment strategies for advanced NMSC.

Keywords: squamous cell carcinoma, basal cell carcinoma, extramammary Paget's disease, merkel cell carcinoma, adnexal carcinoma

\section{INTRODUCTION}

Non-melanoma skin cancers (NMSCs) are the most common forms of human neoplasia, with more than 3 million newly diagnosed cases estimated to occur in the USA every year (1). NMSCs represent a diverse group of skin tumors, including cutaneous squamous cell carcinoma (cSCC), basal cell carcinoma (BCC), extramammary Paget's disease (EMPD), Merkel cell carcinoma (MCC), and skin adnexal carcinomas. Of these, BCC and cSCC account for the majority of NMSCs $(75-80 \%$ and $20-25 \%$ of all NMSC cases, respectively) in Australia $(2,3)$. In addition, the incidence of these disease is increasing. The incidence rates of BCC and CSCC increased by $145 \%$ and 263\%, respectively, from 2000 to 2010 in the United States of America (USA) (4). These increases are associated with several factors, including 
raised awareness of NMSC in the general population, increased number of patients undergoing surgical treatment with confirmed histopathology, improved registration, transition of patient population toward the elderly, and increased exposure to ultraviolent (UV) radiation (5-7). Therefore, NMSC has now become a substantial economic burden $(8,9)$.

NMSCs show differences in progression and metastatic behavior according to each cancer type. MCCs are highly aggressive malignancies with high mortality rates (10). The 5year overall survival (OS) rate of MCC patients with localized disease in USA was reported to be 55.6\%, with historical 5year OS rates of 35.4 and $13.5 \%$ for patients with nodal and distant metastatic disease, respectively (11). On the other hand, BCC, cSCC, and EMPD generally have a favorable prognosis with surgical resection, especially when detected in the early stages. While its precise clinical behavior is unclear due to its rarity, skin adnexal carcinoma is also considered to have low metastatic potential (12). However, once metastasis occurs, the prognosis of these tumors becomes extremely poor. The median OS period of metastatic BCC was reported to be 10.0 months (range, 0.5-108.0 months) after the detection of metastasis (13). The median progression-free survival (PFS) and OS of stage IV cSCC patients were reported to be 0.67 and 2.19 years, respectively, and the 5-year survival rate was $26 \%$ in USA (14). The median OS of EMPD patients with distant metastasis was reported to be 1.5 years with a 5 -year survival rate of $7 \%$ in Japan (15). While chemotherapeutic agents and treatment strategies for these patients were mainly based on the results of isolated small case series or clinical trials in limited numbers of patients, accumulation of pathobiological evidence as well as advances in molecular biotechnology are facilitating the development of novel drugs and therapeutic regimens. This review presents a summary of updates on the treatment of advanced NMSC based mainly on the results of clinical trials with high evidenced level.

\section{BASAL CELL CARCINOMA}

BCCs are common skin cancers arising mainly from the basal layer of the epidermis. Clinically, they tend to appear on sun-exposed skin, especially on the face and neck (16). Generally, BCCs are slow growing and have low metastatic potential. However, deeply invasive or large lesions $>10 \mathrm{~cm}^{2}$ in diameter may show metastasis (17). The estimated metastasis rate ranges from 0.0029 to $0.55 \%$, and common metastatic sites are regional lymph nodes, lungs, bones, skin, and liver $(13,17)$. Pathobiologically, activation of the Hedgehog $(\mathrm{HH})$ signaling pathway has been shown to play a critical role in the majority of cases and is recognized as a therapeutic target (18-20). It was first characterized by identification of a germ line mutation in the patched homolog 1 (PTCH1) gene in basal cell nevus syndrome, which was then reinforced by the discovery of mutations of PTCH1, smoothened homolog $(S M O)$, and other genes related to the $\mathrm{HH}$ signaling pathway in sporadic $\operatorname{BCC}(20,21)$. In general, activation of $\mathrm{HH}$ signaling is initiated by the cell-surface protein, SMO, which is inhibited by another cell-surface protein, PTCH1 (20). Binding of the $\mathrm{HH}$ ligand to PTCH1 prevents this inhibition and thus activates signaling. Mutations in PTCH1 cause loss of its inhibitory role, and mutations in SMO release the inhibition resulting in constitutive signaling activation (Figure 1A) (22-24).

\section{TREATMENT OF ADVANCED BCC}

\section{Chemotherapeutic Agents}

Before the emergence of molecular target therapies, metastatic BCC had been treated with several conventional cytotoxic chemotherapies. However, only a few small case series reported the efficacy of these treatments, due to the rarity of metastatic BCC. In a review of 12 reported cases treated with platinumcontaining regimens, five showed complete response (CR) and four showed partial response (PR) (25).

\section{Molecular Targeting Agents}

Two molecular targeting agents are currently available for treatment of advanced BCC, i.e., vismodegib and sonidegib, which were approved by the U.S. Food and Drug Administration (FDA), USA in 2012 and 2015, respectively. Both are oral small molecule inhibitors of SMO, which block $\mathrm{HH}$ signaling activation (19) (Figure 1A). One open-label trial of vismodegib showed a response rate (RR) of $68.5 \%$ for 1,119 cases of locally advanced BCC (laBCC), including a CR rate of $33.4 \%$ and $\mathrm{PR}$ rate of $35.1 \%$. The RR in 96 metastatic BCC (mBCC) cases was $36.9 \%$, including $4.8 \% \mathrm{CR}$ and $32.1 \% \mathrm{PR}$. The median PFS was 23.2 months in laBCC and 13.1 months in mBCC (26). In a randomized trial, 12-month administration of sonidegib at $200 \mathrm{mg}$ /day showed RR of 57.6 and $7.7 \%$ in $66 \mathrm{laBCCs}$ and $13 \mathrm{mBCCs}$, respectively. Disease control rates, including cases with stable disease, were $91.9 \%$ in laBCC and $92.3 \%$ in $\operatorname{mBCC}(27,28)$. In a meta-analysis of 18 reports, the overall response rates (ORR) were similar for vismodegib and sonidegib in laBCC (68.8 vs. 56.6\%, respectively), but the complete RRs were markedly different (30.9 vs. $3.0 \%$, respectively). In $\mathrm{mBCC}$, the ORR of vismodegib was 2.7 -fold higher than that of sonidegib (39.7 vs. $14.7 \%$, respectively). With regard to side effects, muscle spasms, dysgeusia, and alopecia were noted at similar frequencies for both agents, and their combined prevalence rates were 67.1, 54.1, and 57.7\%, respectively (29).

The antifungal drug, itraconazole, has also been reported to inhibit HH signaling activity by acting on SMO (30). In an openlabel exploratory phase II trial, $42.1 \%$ of cases showed reduction of tumor size and re-epithelization (8/19 cases) (31). Tumor area was reduced by a mean of $24 \%$. Further trials are required to determine its clinical utility.

\section{CUTANEOUS SQUAMOUS CELL CARCINOMA}

Cutaneous squamous cell carcinomas (cSCCs) are the second most common skin cancer in NMSCs. In addition to UV irradiation, several risk factors may cause cSCC, including 


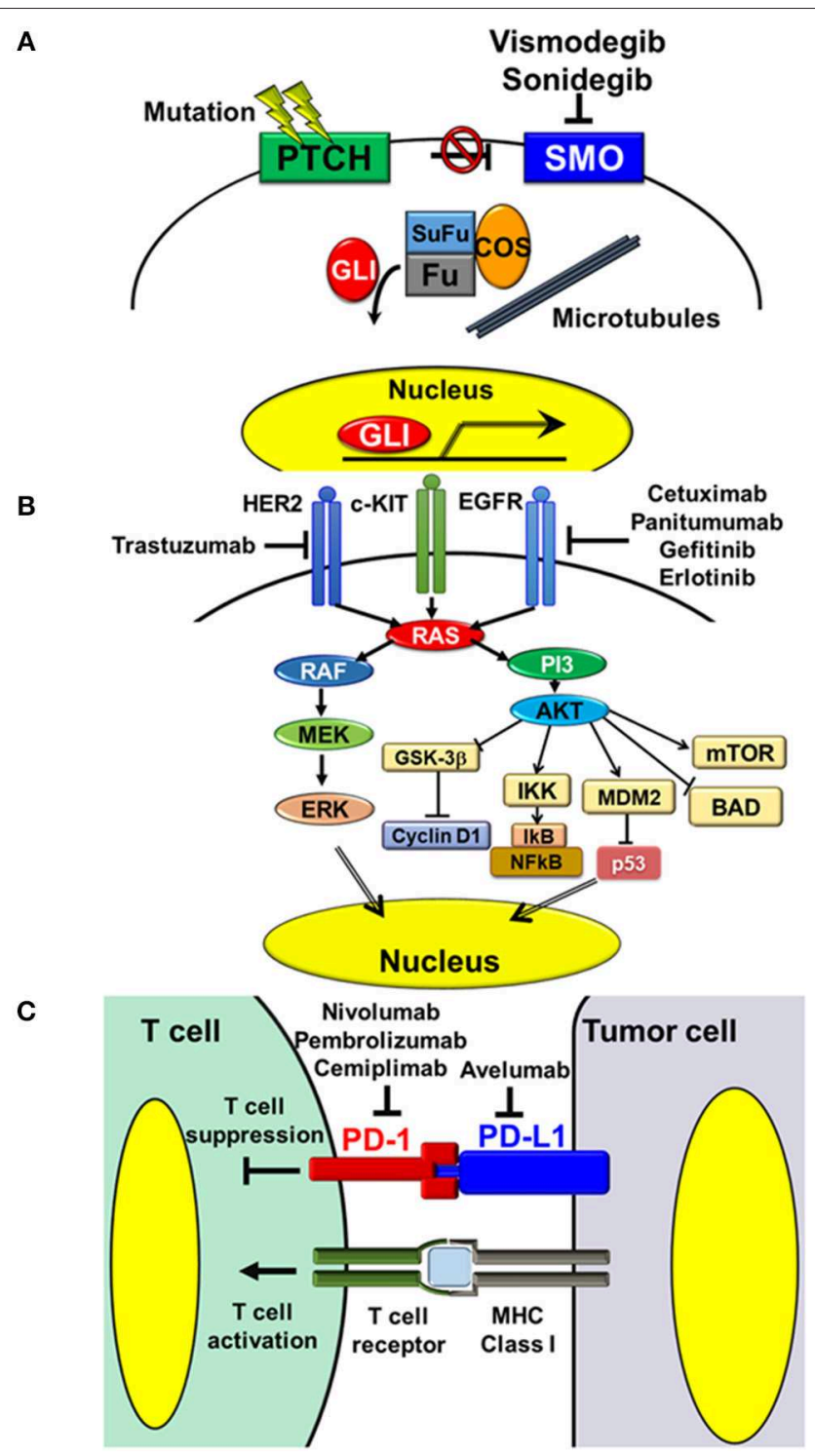

FIGURE 1 | Targeting pathways and molecules in the treatment of NMSC. (A) Hedgehog signaling pathway. Activation of Hedgehog signaling is initiated by the cell-surface protein, SMO, which is inhibited by another cell-surface protein, PTCH1. Binding of the Hedgehog ligand to PTCH1 releases this inhibition and thereby activates the pathway. Mutations in $\mathrm{PTCH} 1$ result in loss of its inhibitory function, while mutations in SMO lead to constitutive signaling activation. Vismodegib and sonidegib are oral small molecule inhibitors of $\mathrm{SMO}$, which block HH signaling activation. (B) Receptor tyrosine kinases and downstream MAPK and PI3-AKT signaling pathways. Aberrant overexpression or mutations of receptor tyrosine kinases, such as EGFR and HER2, cause activation of downstream signaling pathways, thus triggering several tumorigenic processes, including cell proliferation, cell survival, and resistance to apoptosis. The monoclonal antibodies, cetuximab and panitumumab, and the oral small molecules, gefitinib and erlotinib, inhibit the activity of EGFR. The monoclonal antibody, trastuzumab, inhibits the activity of HER2. (C) Interaction between T cells and tumor cells via the PD-1/PD-L1 axis. PD-1/PD-L1 interaction inhibits activation of $T$ cell functions, including Th1 cytokine secretion, T cell proliferation, and cytotoxicity. Inhibition of PD-1/PD-L1 interaction with the anti-human PD-L1 antibody, avelumab, and anti-human PD-1 antibodies, nivolumab, pembrolizumab, and cemiplimab, releases these inhibitions and thereby activates the cytotoxic effects of T cells on tumor cells. ionizing radiation, chemical carcinogen exposure, chronic wounds or scars, immunosuppression, infection with certain genotypes of human papillomavirus (HPV), and genetic abnormalities of genes involved in DNA repair (32-34). While the majority of these lesions can be treated by surgical resection, a small proportion will develop metastasis with significant morbidity and mortality (35). Of all metastatic cases, around $80 \%$ are localized in the regional lymph nodes, with the remainder showing distant metastasis in multiple organs, including the lungs, liver, brain, bones, and skin (32).

Pathobiologically, cSCCs are characterized as tumors with high mutational burdens. Exome-level sequencing of eight primary cSCCs revealed approximately 1,300 somatic singlenucleotide variations per cSCC exome (1/30,000 bp) (36). Among them, several genomic alterations were reported to show strong associations with the development and progression of cSCC. One study regarding single nucleotide and copy number variations in DNA samples extracted from metastatic cSCCs indicated that TP53 (79\% of cases), NOTCH-1/2/4 (69\%), and CDKN2A (48\%) genes were frequently altered and several signaling pathways, including the RAS/RAF/MEK/ERK1/2 MAPK pathway (MAPK pathway) and phosphatidylinositol 3/AKT pathway (PI3-AKT pathway), are frequently activated (45\% of cases) (37). Inactivating mutation of TP53 due to UV irradiation has been reported to be a cause of cutaneous malignancy with loss of programmed cell death in abnormal squamous cells (38). Loss of NOTCH-1 was reported to be associated with disease progression (39). CDKN2A encodes two cell cycle regulatory proteins, p16 and p14, loss of which causes aberrant mitosis (40). In addition, several reports indicated aberrant overexpression or mutations of epidermal growth factor receptor (EGFR) in cSCC samples. EGFR belongs to the receptor tyrosine kinase (RTK) family that activates several downstream signaling pathways, including MAPK and PI3-AKT pathways, and is involved in various cellular processes, including cell proliferation and survival $(41,42)$ (Figure 1B).

\section{TREATMENT OF ADVANCED CSCC}

\section{Chemotherapeutic Agents}

Chemotherapeutic agents commonly utilized in treatment of advanced cSCC include bleomycin, platinum, anthracycline, taxanes, interferon alpha, 5-fluorouracil, and its precursor drug capecitabine (43-49). While there have been a number of reports of the efficacies of chemotherapeutic regimens combining these agents, the level of evidence was generally poor as the trials had several limitations, such as small sample size, heterogeneous patient populations, and lack of randomization.

\section{Molecular Targeting Agents}

Based on the frequent aberrant overexpression or mutations of EGFR in cSCC, the utility of agents targeting EGFR has been suggested (Figure 1B). The efficacy and safety of the monoclonal antibodies, cetuximab, and panitumumab, and oral small molecules, gefitinib and erlotinib, have been reported in several clinical trials and retrospective studies in small patient 
populations. Cetuximab was evaluated prospectively in a phase II study in 36 cases of advanced cSCC, including three metastatic and 33 locally advanced cSCCs in France. The ORR was $27.8 \%$, including two cases of $\mathrm{CR}$ and eight cases of PR, the rate of stable disease was $41.7 \%$ (15/36 cases), and the overall disease control rate was $69.4 \%$ (25/36 cases). The most common grade 3 and 4 toxicities were infection $(22.2 \%)$ and bleeding from the tumor (11.1\%) (50). In a retrospective study in 34 locally advanced cSCC patients in France treated with cetuximab alone or in combination with platinum and 5-fluorouracil as neoadjuvant therapy, the RR of cetuximab alone patients was 55.5\% (5/9 cases), including three cases of complete histological response, while that of combination therapy patients was $92 \%(23 / 25$ cases), including 15 cases of complete histological response (51). The utility of panitumumab was evaluated in a small phase II study in 16 patients with advanced cSCC in Australia. The ORR was $31.3 \%$ (5/16 cases), including two cases of CR (52). While monoclonal antibodies showed certain RRs, oral small molecules showed limited efficacy for advanced cSCC. In phase II studies conducted in USA, gefitinib and erlotinib only showed PR rates of $15 \%$ (5/40 cases) and $10.3 \%$ (3/29 cases), respectively $(53,54)$.

\section{Immune Checkpoint Inhibitors}

Recent advances in cancer immunotherapy have provided new therapeutic approaches involving blocking of immune checkpoints. In particular, antibodies targeting PD-1 and its ligand, programmed cell death ligand 1 (PD-L1), have been reported to have prospective efficacy in various cancer types (55) (Figure 1C). The same applies to advanced cSCC; administration of the anti-PD-1 monoclonal antibody, cemiplimab, showed impressive efficacy. Utility of cemiplimab in a phase I expansion cohort study including 16 metastatic and 10 locally advanced cSCCs showed ORR of 50\% (13/26 cases) and a durable disease control rate of $65.4 \%$ (17/26 cases). Duration of response exceeded 6 months in $53.8 \%$ (7/13 cases) of patients who showed a response. In a phase II study in 59 cases of metastatic cSCC, the ORR was $47.5 \%$ (28/59 cases), including four cases of $\mathrm{CR}$, the durable disease control rate was $61.0 \%$ (36/59 cases), and the duration of response exceeded 6 months in $57.1 \%$ (16/28 cases) of patients who showed a response. By integrating the results of these two studies, the RR of cemiplimab for metastatic cSCC was $46.7 \%$ (35/75 cases). As high mutational and neoantigenic burdens have been reported to be strong predictors of responsiveness to immunotherapy, cSCC is expected to be responsive to immune checkpoint inhibitors. Safety assessment evaluation indicated that treatment was well-tolerated. The most common adverse events in the above phase II study were diarrhea (27.1\%), fatigue (23.7\%), nausea (16.9\%), constipation (15.3\%), and rash (15.3\%). The observed grade 3 and 4 toxicities were infection (22.2\%) and tumor bleeding (11.1\%). The most common grade 3 and 4 toxicity was pneumonitis (3.4\%), and no severe toxicities were present in more than $5 \%$ of patients (56). Based on these observations, cemiplimab was approved by the FDA, USA in 2018 for treatment of advanced cSCC.

\section{EXTRAMAMMARY PAGET'S DISEASE}

EMPD is a rare intraepithelial adenocarcinoma that principally affects the genital and axillary regions. EMPD typically grows slowly and is diagnosed as an in situ lesion, and it generally shows favorable prognosis with surgical resection. However, once it invades the dermis, EMPD easily causes metastasis and the prognosis becomes poor (57). Although its pathogenesis remains to be clarified, it has been reported to resemble breast cancer in its immunohistochemical and molecular profiles (58).

Pathobiologically, human epidermal growth factor receptor 2 (HER2) has been reported be overexpressed in 15-60\% of EMPD cases, mainly based on amplification of the HER2 gene (59-61). HER2 is a member of the RTKs, which regulate several downstream pathways, including MAPK and PI3-AKT pathways $(42,62)$ (Figure 1B). HER2 gene amplification causes HER2 protein overexpression, resulting in ligand-independent homodimerization and aberrant activation of downstream signaling pathways (63). Of note, immunohistochemical staining for phosphorylated ERK and phosphorylated AKT, which are signatures reflecting activation of MAPK and PI3-AKT pathways, respectively, are positive even in HER2-negative cases (59, 61). A recent report indicated that $81.3 \%$ (13/16 cases) of Japanese metastatic EMPDs are positive for phosphorylated ERK and phosphorylated AKT regardless of the HER2 expression status, and $68.8 \%$ (11/16 cases) were positive for both signatures (61). Furthermore, DNA sequence analysis of EMPD revealed that $19 \%$ of cases had mutant RAS or RAF genes and $35 \%$ of cases had mutations in PIK3CA, which encodes the catalytic subunit of PI3K, or in AKT1 that activates these pathways, suggesting that these two signaling pathways play critical roles in the pathogenesis of EMPD (64).

Signaling through androgen hormone receptor (AR) was also reported to be associated with the development of EMPD. The AR-positive rate in EMPD has been reported to be $54-90 \%$, and its level of expression was significantly higher in invasive EMPD than non-invasive $\operatorname{EMPD}(65,66)$. Moreover, the expression levels of the androgen-producing enzymes, $5 \alpha$-reductase and $17 \beta$-hydroxysteroid dehydrogenase type 5 , were shown to be higher in invasive EMPD than non-invasive $\operatorname{EMPD}(66,67)$. These results suggested an association between androgen-AR signaling and the progression of EMPD.

\section{TREATMENT OF METASTATIC EMPD}

\section{Chemotherapeutic Agents}

At present, no chemotherapeutic agents have yet been approved for the treatment of metastatic EMPD. Several cytotoxic chemotherapeutic regimens have been used to treat metastatic EMPD, such as combination of low-dose 5-fluorouracil and cisplatin (FP therapy), combination of 5-fluorouracil, epirubicin, carboplatin, vincristine, and mitomycin C (FECOM therapy), combination of cisplatin, epirubicin and paclitaxel (PET therapy), combination of docetaxel and S-1, docetaxel monotherapy, and S-1 monotherapy (68-76). In general, certain patient populations initially respond well to these therapies. 
However, the efficacies are usually temporary, and tumors soon recur due to acquisition of resistance. Low-dose FP and FECOM regimens showed RR of 59 and $57 \%$ with median PFS of 5.2 and 6.5 months as first-line treatment in Japanese metastatic EMPD patients, respectively. However, the median OS rate was $<1$ year $(68,69)$. The DTX monotherapy for Japanese metastatic EMPD patients was reported to show an RR of $58 \%$, but its median PFS and OS were 7.1 and 16.6 months, respectively (70). Nevertheless, modification of the treatment schedule or improvement of the chemotherapeutic regimen may enhance the efficacy. In PET therapy, adjustment of the dosing interval enabled Japanese metastatic EMPD patients to continue treatment by reducing its severe toxicity, while maintaining its high efficacy (76).

\section{Molecular Targeting Agents}

HER2 is recognized as a prospective therapeutic target in cases of advanced HER2-positive EMPD based on the pathobiological similarities to breast cancer and its frequent overexpression in EMPD (Figure 1B). The HER2-specific humanized monoclonal antibody, trastuzumab, is an established treatment option for metastatic HER2-positive breast cancers (77). Several case reports have indicated the effectiveness of trastuzumab in combination with cytotoxic chemotherapeutic agents in EMPD (78-81). Based on these findings, a phase II study of trastuzumab with docetaxel for HER2-positive unresectable or metastatic EMPD (jRCTs031180073) is currently underway in Japan.

For therapy targeting androgen-AR signaling, one case report showed the utility of combined androgen blockade (CAB) therapy consisting of bicalutamide (anti-androgen drug) and leuprolide acetate (LH-RH agonist), which is used in the treatment of prostate cancer. While its efficacy lasted for only 6 months, it significantly reduced multiple bone metastases of EMPD (82).

\section{MERKEL CELL CARCINOMA}

Merkel cell carcinoma (MCC) is a rare but highly aggressive cutaneous neuroendocrine carcinoma (10). While they are named after sensory Merkel cells in the skin based on their ultrastructural and immunophenotypic resemblance, the true origin of MCC tumor cells remains unknown (83). Risk factors for MCC include age $\geq 65$ years, immunosuppression, previous sun exposure, and Merkel cell polyomavirus (MCPyV) infection (84). The majority of MCCs are caused by the integration of $\mathrm{MCPyV}$ into the genome, and the remainder are associated with exposure to UV irradiation $(84,85)$.

$\mathrm{MCPyV}$ is a non-enveloped double-stranded DNA virus that belongs to the polyomavirus family and is highly prevalent in the general population. Primary $\mathrm{MCPyV}$ infection usually occurs during childhood and can be detected in the skin of nearly all healthy individuals. Despite its widespread infection, MCC develops in only a small percentage of the population. The viral oncogenes, LT and sT antigens, have been suggested to play important roles in MCPyV-induced tumorigenesis. LT antigen has been shown to bind to retinoblastoma (RB) protein, inactivating its tumor suppressive function (86). sT is the major viral oncogene that contributes to virally induced cellular transformation (87). It can maintain the hyperphosphorylated and inactivated state of the eukaryotic translational initiation factor $4 \mathrm{E}$-binding protein 1 (4E-BP1), ultimately leading to acceleration of cell proliferation and malignant transformation (87). sT also inhibits the cellular ubiquitin ligase, SCFFbw7, and suppresses proteasomal degradation of MCPyV LT and other cell cycle regulators, thus contributing to viral replication and host cell transformation (88). The viral DNA was shown to be clonally integrated into the genome of MCC cells (84).

Integration of $\mathrm{MCPyV}$ has also been reported to be associated with immunogenicity of $\operatorname{MCC}(84,89)$. Several reports indicated that $\mathrm{MCPyV}$-positive tumor cells express viral antigens at high levels, which are recognized by the innate and adaptive immune systems (90). In particular, patients with higher immune responses to MCPyV show better disease outcomes than those with modest responses (91, 92). MCPyV-negative MCCs may also have immunogenicity, based on their high mutational burden and neoantigens generated by exposure to $\mathrm{UV}$ irradiation. In fact, $\mathrm{MCPyV}$ negative MCCs have more gene mutations than cells in most other cancer types (85). Furthermore, about $50 \%$ of MCCs have been reported to express PD-1 on tumorinfiltrating lymphocytes and PD-L1 on tumor cells or infiltrating macrophages (93).

\section{TREATMENT OF ADVANCED MCC}

\section{Chemotherapeutic Agents}

Several cytotoxic chemotherapies have been preferred as treatment options for advanced MCC. Chemotherapeutic regimens were designed based on those used in small cell lung cancer (94). These include combination of platinum and etoposide, combination of cyclophosphamide, doxorubicin (or epirubicin) and vincristine, and monotherapies of topotecan and etoposide (95). Although MCC shows a relatively high $\mathrm{RR}$ to first-line chemotherapy, the response is rarely durable, and resistance develops quickly. One retrospective study has reported RRs of 69 and $57 \%$ to first-line chemotherapy for locally advanced and metastatic MCC, respectively, but survival was limited to averages of 24 and 9 months, respectively (96).

\section{Immune Checkpoint Inhibitors}

Based on its high immunogenicity, the application of immune checkpoint inhibitors for MCC has been examined in several clinical trials with promising results. In particular, blockade of the $\mathrm{PD}-1 / \mathrm{PD}-\mathrm{L} 1$ interaction prolonged the responses and improved OS of advanced MCC. Avelumab is a monoclonal antihuman PD-L1 antibody, which activates antibody-dependent cell-mediated cytotoxicity as well as blocking PD-1/PD-L1 interactions (Figure 1C). In an international multicenter phase II trial in 88 cytotoxic chemotherapy-refractory metastatic MCC patients, avelumab treatment (10 mg/kg every 2 weeks) showed ORR of 33\% (29/88 cases) over the minimum follow-up period of 2 years (median 29.2 months), including a CR rate of $11 \%(10 / 88$ cases) $(97,98)$. With regard to safety concerns, only $5 \%(4 / 88$ cases) of patients had grade 3 adverse events and there were no 
grade 4 or 5 treatment-related adverse events. In an international, multicenter, single-arm, open-label clinical trial in 39 treatmentnaive patients, avelumab showed ORR of $62.1 \%$ (29/39 cases) at the minimum follow-up period of 3 months, including CR of $13.8 \%$ (4/39 cases) and PR of $48.3 \%$ (14/39 cases) (99). Pembrolizumab is a monoclonal anti-human PD-1 antibody, which also blocks PD-1/PD-L1 interactions (Figure 1C). In a phase II study in 26 systemic therapy-naive stage 3 or 4 MCC patients, administration of pembrolizumab ( $2 \mathrm{mg} / \mathrm{kg}$ every 3 weeks) showed ORR of 56\% (14/25 cases) including CR in four cases and PR in 10 cases. With regard to safety concerns, grade 3 or 4 adverse events occurred in only $15 \%(4 / 26)$ of patients and these were manageable (93). Based on these reports, avelumab and pembrolizumab have now been approved by the FDA, USA for treatment of metastatic MCC. With regard to other agents targeting PD-1/PD-L1 interaction, the anti-human PD-1 antibody, nivolumab, showed efficacy for MCC. In a phase I/II study in 15 treatment-naive and 10 previously treated metastatic MCC patients, administration of nivolumab ( $240 \mathrm{mg}$ every 2 weeks) showed ORR of $68 \%$ (15/22 cases) including CR and PR in three and 12 of 22 evaluable cases, respectively. PFS and OS rates at 3 months were 82 and 92\%, respectively (100).

\section{SKIN ADNEXAL CARCINOMA}

Skin adnexal carcinomas are a group of malignancies exhibiting histopathological features of follicular, sebaceous, apocrine, or eccrine differentiation. Pilomatrix carcinoma, trichilemmal carcinoma, and trichoblastic carcinoma are categorized as those showing follicular differentiation, while sebaceous carcinoma is categorized as those showing sebaceous differentiation. Malignant tumors showing sweat gland differentiation include porocarcinoma, spiradenocarcinoma, hidradenocarcinoma, apocrine adenocarcinoma, microcystic adnexal carcinoma, adenoid cystic carcinoma, malignant mixed tumor, malignant cylindroma, digital papillary carcinoma, syringoid eccrine carcinoma, and mucinous carcinoma of the skin (101). The precise molecular pathogenesis of skin adnexal carcinomas is still under investigation. Whole-exome sequencing of sebaceous carcinomas indicated that they can be divided into three clinically distinct classes: pauci-mutational type harboring fewer mutations, UV damage type with a high mutational burden due to UV damage, and microsatellite instability (MSI) type with microsatellite repeat sequence replication errors. Ocular sebaceous carcinoma belongs to the pauci-mutational type, sebaceous carcinomas associated with Muir-Torre syndrome, a hereditary cancer syndrome associated with germline mutations in mismatch repair pathway components, belongs to the MSI type, and UV damage type skin adnexal carcinomas tend to show poorly differentiated histological features (102). HRAS and EGFR have been suggested to play pathobiological roles in some cases of porocarcinoma (103). Expression of EGFR has also been reported in several sweat gland carcinomas (104). In addition, expression of HER2 (105-107) and c-KIT $(108,109)$ and the activation of MAPK or PI3-AKT signaling pathways have been described in single case reports of several skin adnexal carcinoma types (108-110).

\section{TREATMENT OF SKIN ADNEXAL CARCINOMA}

At present, there are neither approved chemotherapeutic agents nor uniform guidelines for the treatment of skin adnexal carcinoma. Therefore, information regarding the utility of systemic treatments for these diseases is available only in published case reports. In general, skin adnexal carcinomas are considered to be relatively chemoresistant, and the prognosis of their metastatic forms is considered to be poor. Although further studies are needed to clarify the usefulness of proposed treatment options, several reports indicated the efficacy of various chemotherapeutic agents used in combination therapy.

\section{Chemotherapeutic Agents}

With regard to metastatic skin adnexal carcinomas with sweat gland differentiation, one report indicated CR for 16 months in one case with a combination of doxorubicin, mitomycin, vincristine, and 5-fluorouracil followed by maintenance combination therapy consisting of cyclophosphamide, vincristine, and 5-fluorouracil (111). Other reports have also shown the efficacy of various other combinations of drugs, including 5-fluorouracil, thiotepa, and cyclophosphamide (112, 113), anthracycline, cyclophosphamide, vincristine, and bleomycin (114), interferon-alpha and weekly paclitaxel (115), and doxorubicin, mitomycin $\mathrm{C}$, vincristine, and cisplatin (116). Notably, the combination of carboplatin and epirubicin maintained CR for 4 years in a case of porocarcinoma (49).

\section{Molecular Targeting Agents}

With regard to targeted therapy, administration of sunitinib, an oral small molecule, multi-targeted RTK inhibitor, stabilized disease progression over 8 months in a patient with metastatic clear cell hidradenocarcinoma and achieved PR for 10 months in a patient with metastatic trichoblastic carcinoma (117). Administration of trastuzumab showed CR for 7 months in a patient with HER2-positive apocrine carcinoma. Moreover, combination of capecitabine and lapatinib, an oral anti-HER2 targeted therapy, in the same patient achieved CR for 6 months after the metastatic lesion developed resistance to trastuzumab (118).

\section{Immune Checkpoint Inhibitors}

The usefulness of targeting PD-1/PD-L1 interaction has also been reported. The results of immunohistochemical analysis indicated that PD-L1 was expressed in 50\% (12/24) of ocular sebaceous carcinoma cases (119). Administration of anti-human PD-1 antibodies showed efficacy in patients with metastatic sebaceous carcinoma $(120,121)$.

\section{CONCLUSION}

While a standard management strategy for treatment of advanced NMSC has not been established, advances in our molecular biological understanding of NMSC and improvement of drug discovery techniques over the past several decades have facilitated the establishment of novel treatment strategies. Nevertheless, emerging molecular targeting therapies are not 
necessarily effective for all NMSC patients. Development of further treatment options for NMSC is required, especially for rare forms of NMSC, such as skin adnexal carcinomas.

\section{AUTHOR CONTRIBUTIONS}

TF wrote the part of squamous cell carcinoma. IH wrote the part of extramammary Paget's disease. YN wrote the part

\section{REFERENCES}

1. Rogers HW, Weinstock MA, Feldman SR, Coldiron BM. Incidence estimate of nonmelanoma skin cancer (keratinocyte carcinomas) in the US population, 2012. JAMA Dermatol. (2015) 151:1081-6. doi: 10.1001/jamadermatol.2015.1187

2. Buettner PG, Raasch BA. Incidence rates of skin cancer in Townsville, Australia. Int J Cancer. (1998) 78:587-93.

3. Palme CE, MacKay SG, Kalnins I, Morgan GJ, Veness MJ. The need for a better prognostic staging system in patients with metastatic cutaneous squamous cell carcinoma of the head and neck. Curr Opin Otolaryngol Head Neck Surg. (2007) 15:103-6. doi: 10.1097/MOO.0b013e3280586723

4. Muzic JG, Schmitt AR, Wright AC, Alniemi DT, Zubair AS, Olazagasti Lourido JM, et al. Incidence and trends of basal cell carcinoma and cutaneous squamous cell carcinoma: a population-based study in Olmsted County, Minnesota, 2000 to 2010. Mayo Clin Proc. (2017) 92:890-8. doi: 10.1016/j.mayocp.2017.02.015

5. Fears T, Scotto J, Schneiderman M. Mathematical models of age and ultraviolet effects on the incidence of skin cancer among whites in the United States. Am J Epidemiol. (1977) 105:420-7. doi: 10.1093/oxfordjournals.aje.a112400

6. Armstrong B, Cust A. Sun exposure and skin cancer, and the puzzle of cutaneous melanoma. Cancer Epidemiol. (2017) 48:147-56. doi: 10.1016/j.canep.2017.04.004

7. Verkouteren J, Ramdas K, Wakkee M, Nijsten T. Epidemiology of basal cell carcinoma: scholarly review. Br J Dermatol. (2017) 177:359-72. doi: $10.1111 /$ bjd.15321

8. Fransen M, Karahalios A, Sharma N, English DR, Giles GG, Sinclair RD. Non-melanoma skin cancer in Australia. Med J Aust. (2012) 197:565-8. doi: 10.5694/mja12.10654

9. Wu X, Elkin EE, Marghoob AA. Burden of basal cell carcinoma in USA. Future Oncol. (2015) 11:2967-74. doi: 10.2217/fon.15.180

10. Becker JC, Stang A, Hausen AZ, Fischer N, DeCaprino JA, Tothill RW, et al. Epidemiology, biology and therapy of Merkel cell carcinoma: conclusions from the EU project IMMOMEC. Cancer Immunol Immunother. (2018) 67:341-51. doi: 10.1007/s00262-017-2099-3

11. Harms KL, Healy MA, Nghiem P, Sober AJ, Johnson TM, Bichakjian CK, et al. Analysis of prognostic factors from 9387 Merkel cell carcinoma cases forms the basis for the new 8th edition AJCC staging system. Ann Surg Oncol. (2016) 23:3564-71. doi: 10.1245/s10434-016-5266-4

12. Bernárdez C, Requena L. Treatment of malignant cutaneous adnexal neoplasms. Actas Dermosifiliogr. (2018) 109:6-23. doi: 10.1016/j.adengl.2017.11.003

13. Wysong A, Aasi SZ, Tang JY. Update on metastatic basal cell carcinoma: a summary of published cases from 1981 through 2011. JAMA Dermatol. (2013) 149:615-6. doi: 10.1001/jamadermatol.2013.3064

14. Zhu GA, Lynn Su Chang A. Overall and progression-free survival of stage 4 cutaneous squamous cell carcinoma at a single large referral center. J Am Acad Dermatol. (2015) 73:165-6. doi: 10.1016/j.jaad.2015. 03.028

15. Ohara K, Fujisawa Y, Yoshino K, Kiyohara Y, Kadono T, Murata Y, et al. A proposal for a TNM staging system for extramammary Paget disease: retrospective analysis of 301 patients with invasive primary tumors. J Dermatol Sci. (2016) 83:234-9. doi: 10.1016/j.jdermsci.2016. 06.004 of basal cell carcinoma. KT wrote the part of Merkel cell carcinoma and adnexal carcinomas. KT also unified the format of entire manuscript.

\section{FUNDING}

This research was supported by AMED under Grant Number JP17lk0201063.

16. Roenigk RK, Ratz JL, Bailin PL, Wheeland RG. Trends in the presentation and treatment of basal cell carcinomas. J Dermatol Surg Oncol. (1986) 12:860-5. doi: 10.1111/j.1524-4725.1986.tb01993.x

17. von Domarus H, Stevens PJ. Metastatic basal cell carcinoma. Report of five cases and review of 170 cases in the literature. J Am Acad Dermatol. (1984) 10:1043-60. doi: 10.1016/S0190-9622(84)80334-5

18. Tanese K, Emoto K, Kubota N, Fukuma M, Sakamoto M. Immunohistochemical visualization of the signature of activated hedgehog signaling pathway in cutaneous epithelial tumors. J Dermatol. (2018) 45:1181-6. doi: 10.1111/1346-8138.14543

19. Bakshi A, Chaudhary SC, Rana M, Elmets CA, Athar M. Basal cell carcinoma pathogenesis and therapy involving hedgehog signaling and beyond. Mol Carcinog. (2017) 56:2543-57. doi: 10.1002/mc.22690

20. Epstein EH. Basal cell carcinomas: attack of the hedgehog. Nat Rev Cancer. (2008) 8:743-54. doi: 10.1038/nrc2503

21. Hatta N, Hirano T, Kimura T, Hashimoto K, Mehregan DR, Ansai S, et al. Molecular diagnosis of basal cell carcinoma and other basaloid cell neoplasms of the skin by the quantification of Glil transcript levels. J Cutan Pathol. (2005) 32:131-6. doi: 10.1111/j.0303-6987.2005.00264.x

22. Pellegrini C, Maturo MG, Di Nardo L, Ciciarelli V, Gutiérrez GarcíaRodrigo C, Fargnoli MC. Understanding the molecular genetics of basal cell carcinoma. Int J Mol Sci. (2017) 18:2485. doi: 10.3390/ijms18112485

23. Johnson RL, Rothman AL, Xie J, Goodrich LV, Bare JW, Bonifas JM, et al. Human homolog of patched, a candidate gene for the basal cell nevus syndrome. Science. (1996) 272:1668-71. doi: 10.1126/science.272.5268.1668

24. Xie J, Murone M, Luoh SM, Ryan A, Gu Q, Zhang C, et al. Activating smoothened mutations in sporadic basal-cell carcinoma. Nature. (1998) 391:90-2. doi: 10.1038/34201

25. Carneiro BA, Watkin WG, Mehta UK, Brockstein BE. Metastatic basal cell carcinoma: complete response to chemotherapy and associated pure red cell aplasia. Cancer Investig. (2006) 24:396-400. doi: 10.1080/07357900600705474

26. Basset-Séguin N, Hauschild A, Kunstfeld R, Grob J, Dréno B, Mortier L, et al. Vismodegib in patients with advanced basal cell carcinoma: primary analysis of STEVIE, an international, open-label trial. Eur J Cancer. (2017) 86:334-48. doi: 10.1016/j.ejca.2017.08.022

27. Migden MR, Guminski A, Gutzmer R, Dirix L, Lewis KD, Combemale $\mathrm{P}$, et al. Treatment with two different doses of sonidegib in patients with locally advanced or metastatic basal cell carcinoma (BOLT): a multicentre, randomised, double-blind phase 2 trial. Lancet Oncol. (2015) 16:716-28. doi: 10.1016/S1470-2045(15)70100-2

28. Dummer R, Guminski A, Gutzmer R, Dirix L, Lewis KD, Combemale P, et al. The 12-month analysis from basal cell carcinoma outcomes with LDE225 Treatment (BOLT): a phase II, randomized, double blind study of sonidegib in patients with advanced basal cell carcinoma. J Am Acad Dermatol. (2016) 75:113-25. doi: 10.1016/j.jaad.2016.02.1226

29. Xie P, Lefrançois P. Efficacy, safety, and comparison of sonic hedgehog inhibitors in basal cell carcinomas: a systematic review and meta-analysis. J Am Acad Dermatol. (2018) 79:1089-110.E.17. doi: 10.1016/j.jaad.2018.07.004

30. Kim J, Tang JY, Gong R, Kim J, Lee JJ, Clemons KV, et al. Itraconazole, a commonly used antifungal that inhibits Hedgehog pathway activity and cancer growth. Cancer Cell. (2010) 17:388-99. doi: 10.1016/j.ccr.2010.02.027

31. Kim DJ, Kim J, Spaunhurst K, Montoya J, Khodosh R, Chandra K, et al. Open-label, exploratory phase II trial of oral itraconazole for 
the treatment of basal cell carcinoma. J Clin Oncol. (2014) 32:745-51. doi: 10.1200/JCO.2013.49.9525

32. Alam M, Ratner D. Cutaneous squamous-cell carcinoma. $N$ Engl J Med. (2001) 344:975-83. doi: 10.1056/NEJM200103293441306

33. Shterzer N, Heyman D, Shapiro B, Yaniv A, Jackman A, Serour F, et al. Human papillomavirus types detected in skin warts and cancer differ in their transforming properties but commonly counteract UVB induced protective responses in human keratinocytes. Virology. (2014) 468-70:64759. doi: 10.1016/j.virol.2014.09.015

34. Euvrard S, Kanitakis J, Claudy A. Skin cancers after organ transplantation. $N$ Engl J Med. (2003) 348:1681-91. doi: 10.1056/NEJMra022137

35. Karia PS, Han J, Schmults CD. Cutaneous squamous cell carcinoma: estimated incidence of disease, nodal metastasis, and deaths from disease in the United States, 2012. J Am Acad Dermatol. (2013) 68:957-66. doi: 10.1016/j.jaad.2012.11.037

36. Durinck S, Ho C, Wang NL, Liao W, Jakkula LR, Collisson EA, et al. Temporal dissection of tumorigenesis in primary cancers. Cancer Discov. (2011) 1:137-43. doi: 10.1158/2159-8290.CD-11-0028

37. Li YY, Hanna GJ, Laga AC, Haddad RI, Lorch JH, Hammerman PS. Genomic analysis of metastatic cutaneous squamous cell carcinoma. Clin Cancer Res. (2015) 21:1447-56. doi: 10.1158/1078-0432.CCR-14-1773

38. Armstrong BK, Kricker A. The epidemiology of UV induced skin cancer. J Photochem Photobiol B. (2001) 63:8-18. doi: 10.1016/S1011-1344(01)00198-1

39. Agrawal N, Frederick MJ, Pickering CR, Bettegowda C, Chang K, Li $\mathrm{RJ}$, et al. Exome sequencing of head and neck squamous cell carcinoma reveals inactivating mutations in NOTCH1. Science. (2011) 333:1154-7. doi: $10.1126 /$ science. 1206923

40. Kim M, Yim SH, Cho NS, Kang SH, Ko DH, Oh B, et al. Homozygous deletion of CDKN2A (p16, p14) and CDKN2B (p15) genes is a poor prognostic factor in adult but not in childhood B-lineage acute lymphoblastic leukemia: a comparative deletion and hypermethylation study. Cancer Genet Cytogenet. (2009) 195:59-65. doi: 10.1016/j.cancergencyto.2009.06.013

41. Uribe P, Gonzalez S. Epidermal growth factor receptor (EGFR) and squamous cell carcinoma of the skin: molecular bases for EGFR-targeted therapy. Pathol Res Pract. (2011) 207:337-42. doi: 10.1016/j.prp.2011.03.002

42. Yarden Y, Sliwkowski MX. Untangling the ErbB signalling network. Nat Rev Mol Cell Biol. (2001) 2:127-37. doi: 10.1038/35052073

43. Bejar C, Maubec E. Therapy of advanced squamous cell carcinoma of the skin. Curr Treat Options Oncol. (2014) 15:302-20. doi: $10.1007 / \mathrm{s} 11864-014-0280-\mathrm{x}$

44. Cartei G, Cartei F, Interlandi G, Meneghini G, Jop A, Zingone G, et al. Oral 5-fluorouracil in squamous cell carcinoma of the skin in the aged. Am J Clin Oncol. (2000) 2:181-4. doi: 10.1097/00000421-20000400 0-00015

45. Report of Medical Research Council Working Party on Bleomycin. Bleomycin in advanced squamous cell carcinoma: a random controlled trial. Br Med J. (1976) 6003:188-90.

46. Sadek H, Azli N, Wendling JL, Cvitkovic E, Rahal M, Mamelle G, et al. Treatment of advanced squamous cell carcinoma of the skin with cisplatin, 5-fluorouracil, and bleomycin. Cancer. (1990) 8:1692-6.

47. Wollina U, Hansel G, Koch A, Köstler E. Oral capecitabine plus subcutaneous interferon alpha in advanced squamous cell carcinoma of the skin. J Cancer Res Clin Oncol. (2005) 5:300-4. doi: 10.1007/s00432-004-0656-6

48. Brewster AM, Lee JJ, Clayman GL, Clifford JL, Reyes MJ, Zhou X, et al. Randomized trial of adjuvant 13-cis-retinoic acid and interferon alfa for patients with aggressive skin squamous cell carcinoma. J Clin Oncol. (2007) 15:1974-8. doi: 10.1200/JCO.2006.05.9873

49. Nakamura Y, Tanese K, Hirai I, Kawakami Y, Funakoshi T. Carboplatin and epirubicin combination therapy for advanced malignant epithelial skin tumors: retrospective study of six patients. J Dermatol. (2018) 45:874-5. doi: $10.1111 / 1346-8138.14328$

50. Maubec E, Petrow P, Scheer-Senyarich I, Duvillard P, Lacroix L, Gelly J, et al. Phase II study of cetuximab as first-line single-drug therapy in patients with unresectable squamous cell carcinoma of the skin. J Clin Oncol. (2011) 29:3419-26. doi: 10.1200/JCO.2010.34.1735

51. Reigneau M, Robert C, Routier E, Mamelle G, Moya-Plana A, Tomasic G, et al. Efficacy of neoadjuvant cetuximab alone or with platinum salt for the treatment of unresectable advanced nonmetastatic cutaneous squamous cell carcinomas. Br J Dermatol. (2015) 173:527-34. doi: 10.1111/bjd.13741

52. Foote MC, McGrath M, Guminski A, Hughes BG, Meakin J, Thomson $\mathrm{D}$, et al. Phase II study of single-agent panitumumab in patients with incurable cutaneous squamous cell carcinoma. Ann Oncol. (2014) 25:204752. doi: 10.1093/annonc/mdu368

53. William WN Jr, Feng L, Ferrarotto R, Ginsberg L, Kies M, Lippman S, et al. Gefitinib for patients with incurable cutaneous squamous cell carcinoma: a single-arm phase II clinical trial. J Am Acad Dermatol. (2017) 77:1110-13. doi: 10.1016/j.jaad.2017.07.048

54. Gold KA, Kies MS, William WN Jr, Johnson FM, Lee JJ, Glisson BS. Erlotinib in the treatment of recurrent or metastatic cutaneous squamous cell carcinoma: a single-arm phase 2 clinical trial. Cancer. (2018) 124:2169-73. doi: $10.1002 /$ cncr. 31346

55. Gentzler R, Hall R, Kunk PR, Gaughan E, Dillon P, Slingluff CL Jr, et al. Beyond melanoma: inhibiting the PD-1/PD-L1 pathway in solid tumors. Immunotherapy. (2016) 8:583-600. doi: 10.2217/imt-2015-0029

56. Migden MR, Rischin D, Schmults CD, Guminski A, Hauschild A, Lewis KD, et al. PD-1 blockade with cemiplimab in advanced cutaneous squamous-cell carcinoma. N Engl J Med. (2018) 379:341-51. doi: 10.1056/NEJMoa1805131

57. Hegarty PK, Suh J, Fisher MB, Taylor J, Nguyen TH, Ivan D, et al. Penoscrotal extramammary Paget's disease: the University of Texas M.D. Anderson Cancer Center contemporary experience. J Urol. (2011) 186:97102. doi: 10.1016/j.juro.2011.02.2685

58. Tessier-Cloutier B, Asleh-Aburaya K, Shah V, McCluggage WG, Tinker A, Gilks CB. Molecular subtyping of mammary-like adenocarcinoma of the vulva shows molecular similarity to breast carcinomas. Histopathology. (2017) 71: 446-52. doi: 10.1111/his.13239

59. Ogawa T, Nagashima Y, Wada H, Akimoto K, Chiba Y, Nagatani T, et al. Extramammary Paget's disease: analysis of growth signal pathway from the human epidermal growth factor receptor 2 protein. Human Pathol. (2005) 36:1273-80. doi: 10.1016/j.humpath.2005.09.009

60. Hikita T, Ohtsuki Y, Maeda T, Furihara M. Immunohistochemical and fluorescence in situ hybridization studies on noninvasive and invasive extramammary Paget's disease. Int J Surg Pathol. (2012) 20:441-8. doi: $10.1177 / 1066896912444159$

61. Hirai I, Tanese K, Nakamura Y, Otsuka A, Fujisawa Y, Yamamoto $\mathrm{Y}$, et al. Assessment of the methods used to detect HER2-positive advanced extramammary Paget's disease. Med Oncol. (2018) 35:92. doi: 10.1007/s12032-018-1154-z

62. Cho HS, Mason K, Ramyar KX, Stanley AM, Gabelli SB, Denney DW Jr, et al. Structure of the extracellular region of HER2 alone and in complex with the herceptin Fab. Nature. (2003) 421:756-60. doi: 10.1038/nature01392

63. Chazin VR, Kaleko M, Miller AD, Slamon DJ. Transformation mediated by the human HER-2 gene independent of the epidermal growth factor receptor. Oncogene. (1992) 7:1859-66.

64. Kang Z, Xu F, Zhang QA, Wu Z, Zhang X, Xu J, et al. Oncogenic mutations in extramammary Paget's disease and their clinical relevance. Int $J$ Cancer. (2013) 132:824-31. doi: 10.1002/ijc.27738

65. Diaz de Leon E, Carcangiu ML, Prieto VG, McCue PA, Burchette JL, To G, et al. Extramammary Paget disease is characterized by the consistent lack of estrogen and progesterone receptors but frequently expresses androgen receptor. Am J Clin Pathol. (2000) 113:572-5. doi: 10.1309/P756-XXCB-TV71-U4XV

66. Azmahani A, Nakamura Y, Ozawa Y, McNamara KM, Fujimura T, Haga $\mathrm{T}$, et al. Androgen receptor, androgen-producing enzymes and their transcription factors in extramammary Paget disease. Hum Pathol. (2015) 46:1662-9. doi: 10.1016/j.humpath.2015.07.007

67. Kasashima S, Ozaki S, Kawashima A, Zen Y, Moriya T, Inoue M. Androgen receptor and 5alpha-reductase immunohistochemical profiles in extramammary Paget disease. Br J Dermatol. (2010) 162:1098-102. doi: $10.1111 / j .1365-2133.2009 .09603 . x$

68. Tokuda Y, Arakura F, Uhara H. Combination chemotherapy of low-dose 5fluorouracil and cisplatin for advanced extramammary Paget's disease. Int $J$ Clin Oncol. (2015) 20:194-7. doi: 10.1007/s10147-014-0686-2

69. Oashi K, Tsutsumida A, Namikawa K, Tanaka R, Omata W, Yamamoto $\mathrm{Y}$, et al. Combination chemotherapy for metastatic extramammary Paget disease. Br J Dermatol. (2014) 170:1354-7. doi: 10.1111/bjd.12788 
70. Yoshino K, Fujisawa Y, Kiyohara Y, Kadono T, Murata Y, Uhara $\mathrm{H}$, et al. Usefulness of docetaxel as first-line chemotherapy for metastatic extramammary Paget's disease. J Dermatol. (2016) 43:633-7. doi: 10.1111/1346-8138.13200

71. Mikoshiba Y, Uhara H, Kubo H, Okuyama R. S-1 induced a durable response in metastatic extramammary Paget's disease. J Dermatol. (2013) 40:664-5. doi: 10.1111/1346-8138.12177

72. Kato J, Hida T, Yamashita T, Kamiya S, Horimoto K, Sato S, et al. Successful TS-1 monotherapy as the second-line treatment for advanced extramammary Paget's disease: a report of two cases. J Dermatol. (2018) 45:80-2. doi: 10.1111/1346-8138.14017

73. Matsushita S, Yonekura K, Mera K, Kawai K, Kanekura T. Successful treatment of metastatic extramammary Paget's disease with S-1 and docetaxel combination chemotherapy. J Dermatol. (2011) 38:996-8. doi: 10.1111/j.1346-8138.2010.01149.x

74. Ogata D, Hokama Y, Tsuchida T. Successful treatment of bilateral multiple lymph node metastases in extramammary Paget's disease with surgery and sequential chemotherapy of S-1 and docetaxel. J Dermatol. (2015) 42:1193-4. doi: 10.1111/1346-8138.13089

75. Egashira S, Kajihara I, Kanemaru H, Uemura-Kiyohara M, YamadaKanazawa S, Nakahara S, et al. Achieved good response of S-1 and docetaxel combination chemotherapy in two patients with metastatic extramammary Paget's disease. J Dermatol. (2017) 44:e103-4. doi: 10.1111/1346-8138.13693

76. Hirai I, Tanese K, Nakamura Y, Ishii M, Kawakami Y, Funakoshi T. Combination cisplatin-epirubicin-paclitaxel therapy for metastatic extramammary paget's disease. Oncologist. (2019) 24:e394-6. doi: 10.1634/theoncologist.2018-0856

77. Baselga J, Carbonell X, Castaneda-Soto NJ, Clemens M, Green M, Harvey V, et al. Phase II study of efficacy, safety, and pharmacokinetics of trastuzumab monotherapy administered on 3-weekly schedules. J Clin Oncol. (2005) 23:2162-71. doi: 10.1200/JCO.2005.01.014

78. Wakabayashi S, Togawa Y, Yoneyama K, Suehiro K, Kambe N, Matsue H. Dramatic clinical response of relapsed metastatic extramammary Paget's disease to trastuzumab monotherapy. Case Rep Dermatol Med. (2012) 2012:401362. doi: 10.1155/2012/401362

79. Takahagi S, Noda H, Kamegashira A, Madokoro N, Hori I, Shindo H, et al. Metastatic extramammary Paget's disease treated with paclitaxel and trastuzumab combination chemotherapy. J Dermatol. (2009) 36:457-61. doi: 10.1111/j.1346-8138.2009.00676.x

80. Hanawa F, Inozume T, Harada K, Kawamura T, Shibagaki N, Shimada S. A case of metastatic extramammary Paget's disease responding to trastuzumab plus paclitaxel combination therapy. Case Rep Dermatol. (2011) 3:223-7. doi: $10.1159 / 000333002$

81. Barth P, Al-Saleem ED, Edwards KW, Millis SZ, Wong YN, Geynisman DM. Metastatic extramammary Paget's disease of scrotum responds completely to single agent trastuzumab in a hemodialysis patient: case report, molecular profiling and brief review of the literature. Case Rep Oncol Med. (2015) 2015:895151. doi: 10.1155/2015/8 95151

82. Yoneyama K, Kamada N, Kinoshita K, Kawashima T, Otani M, Endo $\mathrm{H}$, et al. Androgen-deprivation regimen for multiple bone metastases of extramammary Paget disease. Br J Dermatol. (2005) 153:853-5. doi: 10.1111/j.1365-2133.2005.06865.x

83. Liu W, MacDonald $\mathrm{M}$, and You J. Merkel cell polyomavirus infection and merkel cell carcinoma. Curr Opin Virol. (2016) 20:20-7. doi: 10.1016/j.coviro.2016.07.011

84. Feng H, Shuda M, Chang Y, Moore PS. Clonal integration of a polyomavirus in human Merkel cell carcinoma. Science. (2008) 319:1096100. doi: $10.1126 /$ science. 1152586

85. Goh G, Walradt T, Markarov V, Blom A, Riaz N, Doumani R, et al. Mutational landscape of MCPyV-positive and MCPyV-negative Merkel cell carcinomas with implications for immunotherapy. Oncotarget. (2016) 7:3403-15. doi: 10.18632/oncotarget.6494

86. Borchert S, Czech-Sioli M, Neumann F, Schmidt C, Wimmer P, Dobner $\mathrm{T}$, et al. High-affinity Rb binding, p53 inhibition, subcellular localization, and transformation by wild-type or tumor-derived shortened Merkel cell polyomavirus large T antigens. J Virol. (2014) 88:3144-60. doi: 10.1128/JVI.02916-13
87. Shuda M, Kwun HJ, Feng H, Chang Y, Moore PS. Human Merkel cell polyomavirus small $\mathrm{T}$ antigen is an oncoprotein targeting the 4E-BP1 translation regulator. J Clin Invest. (2011) 121:3623-34. doi: 10.1172/JCI46323

88. Kwun HJ, Shuda M, Feng H, Camacho CJ, Moore PS, Chang Y. Merkel cell polyomavirus small $\mathrm{T}$ antigen controls viral replication and oncoprotein expression by targeting the cellular ubiquitin ligase SCFFbw7. Cell Host Microbe. (2013) 14:125-35. doi: 10.1016/j.chom.2013.06.008

89. Bhatia S, Afanasiev O, Nghiem P. Immunobiology of Merkel cell carcinoma: implications for immunotherapy of a polyomavirus-associated cancer. Curr Oncol Rep. (2011) 488-97. doi: 10.1007/s11912-011-0197-5

90. Schadendorf D, Nghiem P, Bhatia S, Hauschild A, Saiag P, Mahnke L, et al. Immune evasion mechanisms and immune checkpoint inhibition in advanced Merkel cell carcinoma. Oncoimmunology. (2017) 6:e1338237. doi: 10.1080/2162402X.2017.1338237

91. Miller NJ, Church CD, Dong L, Crispin D, Fitzgibbon MP, Lachance K, et al. Tumor-infiltrating Merkel cell polyomavirus-specific $\mathrm{T}$ cells are diverse and associated with improved patient survival. Cancer Immunol Res. (2017) 5:137-47. doi: 10.1158/2326-6066.CIR-16-0210

92. Paulson KG, Lewis CW, Redman MW, Simonson WT, Lisberg A, Ritter D, et al. Viral oncoprotein antibodies as a marker for recurrence of Merkel cell carcinoma: a prospective validation study. Cancer. (2017) 123:1464-74. doi: $10.1002 /$ cncr.30475

93. Nghiem PT, Bhatia S, Lipson EJ, Kudchadkar RR, Miller NJ, Annamalai L, et al. PD-1 blockade with pembrolizumab in advanced Merkel-cell carcinoma. N Engl J Med. (2016) 374:2542-52. doi: 10.1056/NEJMoa1603702

94. Feun LG, Savaraj N, Legha SS, Silva EG, Benjamin RS, Burgess MA. Chemotherapy for metastatic merkel cell carcinoma. Review of the M.D. Anderson Hospital's experience. Cancer. (1988) 62:683-5. doi: 10.1002/10970142(19880815)62:4<683::AID-CNCR2820620406>3.0.CO;2-J

95. Miller NJ, Bhatia S, Parvathaneni U, Iyer JG, Nghiem P. Emerging and mechanism-based therapies for recurrent or metastatic Merkel cell carcinoma. Curr Treat Options Oncol. (2013) 14:249-63. doi: 10.1007/s11864-013-0225-9

96. Voog E, Biron P, Martin JP, Blay JY. Chemotherapy for patients with locally advanced or metastatic Merkel cell carcinoma. Cancer. (1999) 85:2589-95.

97. Kaufman HL, Russell J, Hamid O, Bhatia S, Terheyden P, D'Angelo SP, et al. Avelumab in patients with chemotherapy-refractory metastatic Merkel cell carcinoma: a multicentre, single-group, open-label, phase 2 trial. Lancet Oncol. (2016) 17:1374-85. doi: 10.1016/S1470-2045(16)30364-3

98. Kaufman HL, Russell JS, Hamid O, Bhatia S, Terheyden P, D’Angelo SP, et al. Updated efficacy of avelumab in patients with previously treated metastatic Merkel cell carcinoma after $\geq 1$ year of follow-up: JAVELIN Merkel 200, a phase 2 clinical trial. J Immunother Cancer. (2018) 6:7. doi: 10.1186/s40425-017-0310-x

99. D’Angelo SP, Russell J, Lebbé C, Chmielowski B, Gambichler T, Grob JJ, et al. Efficacy and safety of first-line avelumab treatment in patients with stage IV metastatic merkel cell carcinoma: a preplanned interim analysis of a clinical trial. JAMA Oncol. (2018) 4:e180077. doi: 10.1001/jamaoncol.2018.0077

100. Topalian SL, Bhatia S, Hollebecque A, Awada A, De Boer JP, Kudchadkar RR, et al. Abstract CT074: Non-comparative, open-label, multiple cohort, phase $1 / 2$ study to evaluate nivolumab (NIVO) in patients with virus-associated tumors (CheckMate 358): efficacy and safety in merkel cell carcinoma (MCC). Cancer Res. (2017) 77:74. doi: 10.1158/1538-7445.AM2017-CT074

101. Patterson JW. Weedon's Skin Pathology. 4th ed. London:ChurchillLivingstone (2016). p. 904-65.

102. North JP, Golovato J, Vaske CJ, Sanborn JZ, Nguyen A, Wu W, et al. Cell of origin and mutation pattern define three clinically distinct classes of sebaceous carcinoma. Nat Commun. (2018) 9:1894. doi: 10.1038/s41467-018-04008-y

103. Harms PW, Hovelson DH, Cani AK, Omata K, Haller MJ, Wang ML, et al. Porocarcinomas harbor recurrent HRAS-activating mutations and tumor suppressor inactivating mutations. Hum Pathol. (2016) 51:25-31. doi: 10.1016/j.humpath.2015.12.015

104. Busam KJ, Tan LK, Granter SR. Epidermal growth factor, estrogen, and progesterone receptor expression in primary sweat gland carcinomas and primary and metastatic mammary carcinomas. Mod Pathol. (1999) 12:786-93. 
105. Hiatt KM, Pilow JL and Smoller BR. Her-2 expression in cutaneous eccrine and apocrine neoplasms. Mod Pathol. (2004) 17:28-32. doi: 10.1038/sj.modpathol.3800007

106. Tanese K, Wakabayashi A, Suzuki T, Miyakawa S. Immunoexpression of human epidermal growth factor receptor-2 in apocrine carcinoma arising in naevus sebaceous, case report. J Eur Acad Dermatol Venereol. (2010) 24:360-2. doi: 10.1111/j.1468-3083.2009.03407.x

107. Wakabayashi A, Tanese K, Yamamoto K, Tanomogi H, Miyakawa S. Extraocular sebaceous carcinoma expressing oestrogen receptor alpha and human epidermal growth factor receptor 2. Clin Exp Dermatol. (2010) 35:546-8. doi: 10.1111/j.1365-2230.2009.03654.x

108. Ohi Y, Kosuge $\mathrm{H}$, Tanese $\mathrm{K}$. Case of syringomatous carcinoma: positive immunohistochemical staining of c-KIT and phosphorylatedextracellular signal-regulated kinase 1/2. J Dermatol. (2015) 42:1191-2. doi: 10.1111/1346-8138.13080

109. Matsumoto N, Hata Y, Tanese K. Case of primary cutaneous adenoid cystic carcinoma: expression of c-KIT and activation of its downstream signaling molecules. J Dermatol. (2015) 42:1109-11. doi: 10.1111/1346-8138.13054

110. Fusumae T, Tanese K, Takeuchi A, Takasugi A, Kawakita R, Shiraishi J, et al. High-grade trichoblastic carcinoma arising through malignant transformation of trichoblastoma: immunohistochemical analysis and the expression of p53 and phosphorylated AKT. J Dermatol. (2019) 46:57-60. doi: 10.1111/1346-8138.14686

111. Coonley CJ, Schauer P, Kelsen DP, Sordillo P, Huvos AG. Chemotherapy of metastatic sweat gland carcinoma. A retrospective review. Am J Clin Oncol. (1985) 8:307-11. doi: 10.1097/00000421-198508000-00006

112. El-Domeiri AA, Brasfield RD, Huvos AG, Strong EW. Sweat gland carcinoma: a clinico-pathologic study of 83 patients. Ann Surg. (1971) 173:270-4. doi: 10.1097/00000658-197102000-00014

113. Shiohara J, Koga H, Uhara H, Takata M and Saida T. Eccrine porocarcinoma: clinical and pathological studies of 12 cases. J Dermatol. (2007) 34:516-22. doi: 10.1111/j.1346-8138.2007.00324.x

114. Mezger J, Remberger K, Schalhorn A, Wohlrab A, Wilmanns W. Treatment of metastatic sweat gland carcinoma by a four drug combination chemotherapy: response in two cases. Med Oncol Tumor Pharmacother. (1986) 3:29-34.

115. Gutermuth J, Audring H, Voit C, Trefzer U, Haas N. Antitumour activity of paclitaxel and interferon-alpha in a case of metastatic eccrine porocarcinoma. J Eur Acad Dermatol Venereol. (2004) 18:477-9. doi: 10.1111/j.1468-3083.2004.00949.x

116. Piedbois P, Breau JL, Morere JF, Israel L. Sweat gland carcinoma with bone and visceral metastases. Prolonged complete remission lasting 16 months as a result of chemotherapy. Cancer. (1987) 60:170-2. doi: 10.1002/10970142(19870715)60:2<170::AID-CNCR2820600208>3.0.CO;2-R

117. Battistella M, Mateus C, Lassau N, Chami L, Boukoucha M, Duvillard $\mathrm{P}$, et al. Sunitinib efficacy in the treatment of metastatic skin adnexal carcinomas: report of two patients with hidradenocarcinoma and trichoblastic carcinoma. J Eur Acad Dermatol Venereol. (2010) 24:199-203. doi: 10.1111/j.1468-3083.2009.03301.x

118. Hidaka T, Fujimura T, Watabe A, Hashimoto A, Haga T, Onami K, et al. Successful treatment of HER-2-positive metastatic apocrine carcinoma of the skin with lapatinib and capecitabine. Acta Derm Venereol. (2012) 92:654-5. doi: 10.2340/00015555-1354

119. Kandl TJ, Sagiv O, Curry JL, Ning J, Ma J, Hudgens CW, et al. High expression of PD-1 and PD-L1 in ocular adnexal sebaceous carcinoma. Oncoimmunology. (2018) 7:e1475874. doi: 10.1080/2162402X.2018.1475874

120. Domingo-Musibay E, Murugan P, Giubellino A, Sharma S, Steinberger D, Yuan J, et al. Near complete response to pembrolizumab in microsatellitestable metastatic sebaceous carcinoma. J Immunother Cancer. (2018) 6:58. doi: 10.1186/s40425-018-0357-3

121. Kodali S, Tipirneni E, Gibson PC, Cook D, Verschraegen C, Lane KA. Carboplatin and pembrolizumab chemoimmunotherapy achieves remission in recurrent, metastatic sebaceous carcinoma. Ophthalmic Plast Reconstr Surg. (2018) 34:e149-51. doi: 10.1097/IOP.0000000000001164

Conflict of Interest Statement: The authors declare that the research was conducted in the absence of any commercial or financial relationships that could be construed as a potential conflict of interest.

Copyright (c) 2019 Tanese, Nakamura, Hirai and Funakoshi. This is an open-access article distributed under the terms of the Creative Commons Attribution License (CC $B Y)$. The use, distribution or reproduction in other forums is permitted, provided the original author(s) and the copyright owner(s) are credited and that the original publication in this journal is cited, in accordance with accepted academic practice. No use, distribution or reproduction is permitted which does not comply with these terms. 